\title{
Surgical excision and contoured custom made splint to treat helical keloid
}

\author{
Ankita Chamaria, Reuben Fernando De Sousa ${ }^{1}$, Meena Ajay Aras, Kennedy Mascarenhas \\ Department of Prosthodontics, Goa Dental College, 'Department of Plastic Surgery, Goa Medical College, Bambolim, \\ Goa, India
}

Address for correspondence: Dr. Ankita Chamaria, D/305, Suncity Complex, 105/1, Biddhannagar Road, Ultadanga, Kolkata - 700 067, India. E-mail: ankita.chamaria12@gmail.com

\section{ABSTRACT}

Helical keloids are difficult to treat as surgical excision requires effective compression of the operative scar to prevent recurrence while retaining the contour and elasticity of the helix. The authors fabricated a conforming custom made post-operative splint from a commonly used dental material. Splints could be fabricated in both pre-operative and post-operative stage.

\section{KEY WORDS}

Ear splint; helix; keloid, pressure therapy

\section{INTRODUCTION}

elical keloids can occur after surgical procedures, piercings, trauma, burns or as secondary keloid formation after prior keloid excision. Several measures have been described for keloid ear lesions such as silicone occlusive dressings, mechanical compression, radiation, cryosurgery, bleomycin, tattooing, intralesional steroids injection, 5-fluorouracil, interferons in combination with excisional surgery. After surgical excision, their rate of recurrence is high (45\%-100\%). Compression of helix has been attempted using polymethylmethacrylate (PMMA) splint, acrylic resin splint and custom designed silicone splints.

\begin{tabular}{|c|c|}
\hline \multicolumn{2}{|c|}{ Video Available on: www.ijps.org } \\
\hline \multicolumn{2}{|c|}{ Access this article online } \\
\hline Quick Response Code: & $\begin{array}{l}\text { Website: } \\
\text { www.ijps.org }\end{array}$ \\
\hline 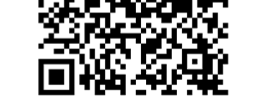 & $\begin{array}{l}\text { DOI: } \\
10.4103 / 0970-0358.197250\end{array}$ \\
\hline
\end{tabular}

The present article describes the fabrication of a custom designed ear splint using ethylene vinyl acetate film retained by undercuts without any compression or silicone lining. It is readily available in daily clinical practice and was successfully used for adjuvant treatment of keloid lesions on the helix.

\section{CASE REPORTS}

\section{Case 1}

A 20-year-old female patient presented with the chief complaint of a keloid on the left helix measuring $10 \mathrm{~mm} \times 6 \mathrm{~mm}$. The occurrence of keloid formation was reported 12 months prior due to ear piercing. No previous therapy had been undertaken [Figure 1].

This is an open access article distributed under the terms of the Creative Commons Attribution-NonCommercial-ShareAlike 3.0 License, which allows others to remix, tweak, and build upon the work non-commercially, as long as the author is credited and the new creations are licensed under the identical terms.

For reprints contact: reprints@medknow.com

How to cite this article: Chamaria A, De Sousa RF, Aras MA, Mascarenhas K. Surgical excision and contoured custom made splint to treat helical keloid. Indian J Plast Surg 2016;49:410-4. 
The treatment decided for the patient was excision followed by compression to prevent recurrence.

\section{Pre-operative splint preparation and mock surgery}

The impression was made of the affected ear before the excision using silicone impression material. Before making the impression, the helical skin was coated with petroleum jelly and ear openings were covered with gauze. Putty (Aquasil, Dentsply) was adapted on the posterior half of the ear [Figure 2]. To ensure orientation of anterior and posterior impressions, notches were made on the rim of the putty. Similarly, putty impression was made of anterior half of the ear. To record the finer details, final impression was made using light body silicone impression material (Aquasil, Dentsply) using the initial putty as a backing [Figure 3]. This negative replica of the ear was poured with dental stone (Kalstone, Kalabhai Dental Private limited) to obtain a positive replica of the ear which will henceforth be mentioned as master die [Figure 4]. The keloid area was marked with a pencil on which mock surgery was to be done. By scraping action using dental carver and burr, keloid was removed from the master die, replicating post-excision ear contour. A 2-mm thick flexible transparent sheet of ethylene vinyl acetate film (Bioplast ${ }^{\circledR}$ ) was pressed in a heat and vacuum press (Biostar, Great Lakes, Orthodontics Ltd.) on the master die to obtain the final conforming splint [Figure 5 and Video 1].

\section{Surgery and splint fitting post-operative}

Intralesional excision of the keloid was performed with tension-free primary closure. The splint was fitted on the patient on the first post-operative day after inspecting for hematoma. The patient was educated regarding use of splint, regular maintenance and local hygiene and need for follow-up for complications and recurrence. She was reviewed monthly with no recurrence at 1 year follow-up [Figure 6].

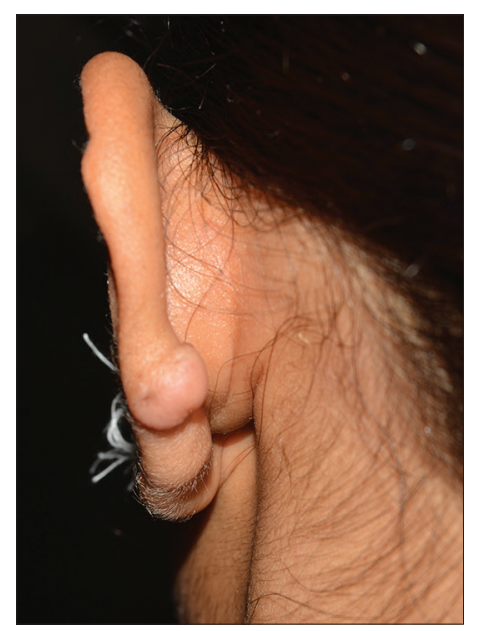

Figure 1: Keloid on posterior helical rim

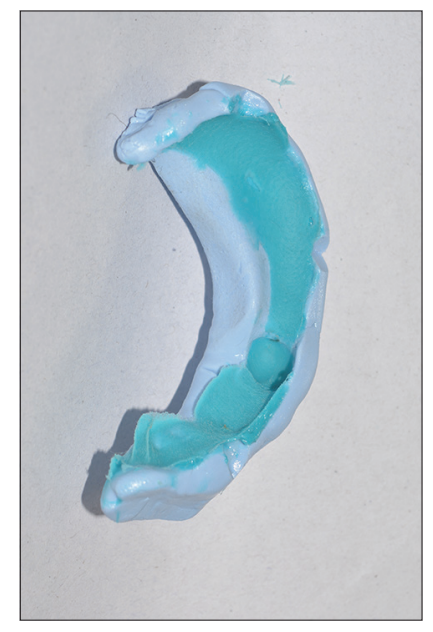

Figure 3: Final negative replica of ear

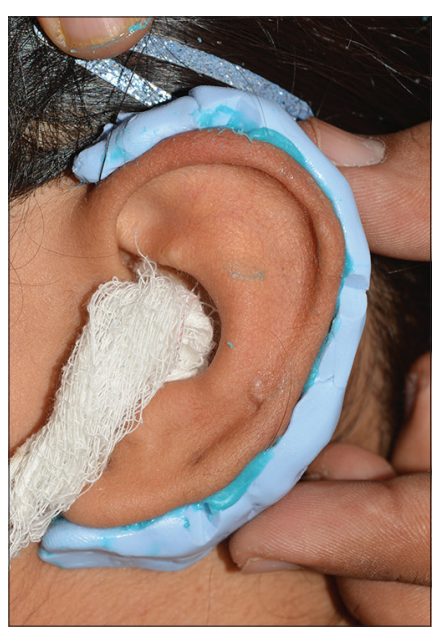

Figure 2: Putty impression of ear

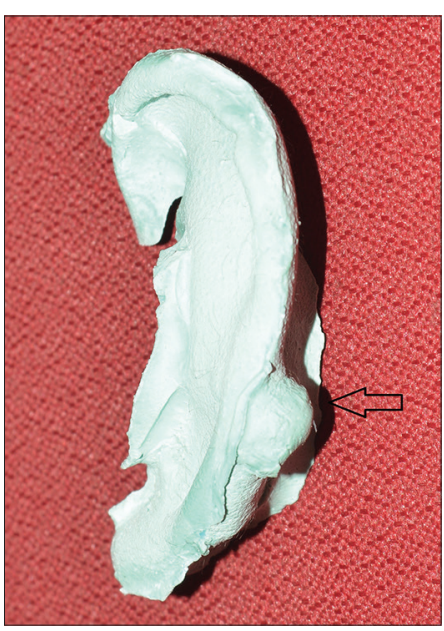

Figure 4: Master die 


\section{Case 2}

A 35-year-old patient reported with helical keloids involving left ear following ear piercing 4 years prior. She had undergone multiple sessions of intralesional steroid injections at another centre to reduce size of the keloid. The keloid was large $(43 \mathrm{~mm} \times 50 \mathrm{~mm})$ and potential for disfigurement of helix post-excision necessitated preserving a keloid fillet flap for primary closure [Figure 7]. The treatment plan was excision followed by compression with custom-made splint and intralesional triamcinolone within the residual keloid scar.

\section{Post-operative splint fabrication and fitting with steroid therapy}

Since final contours of the keloid fillet flap could not be anticipated in laboratory, splint fabrication was deferred to post-operative period. Intralesional excision with fillet flap closure and intraoperative steroid injection was

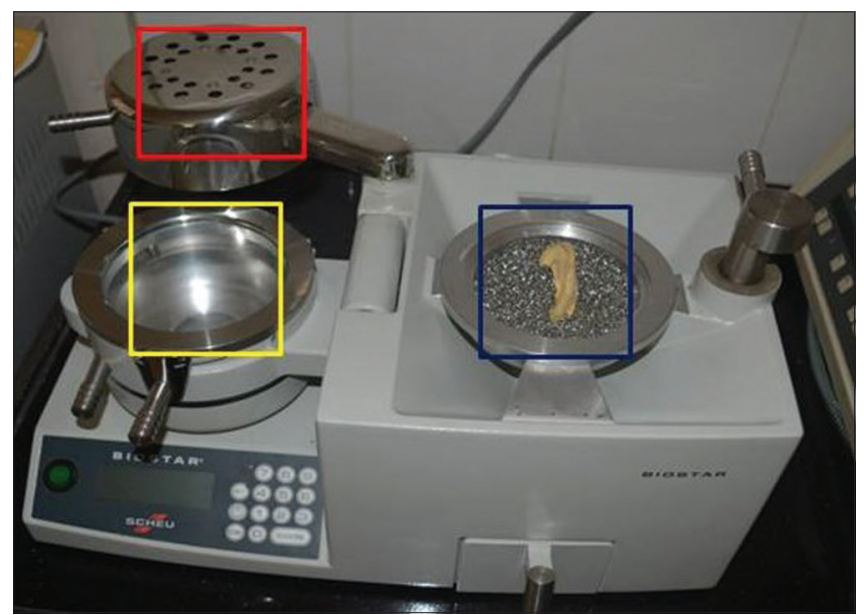

Figure 5: Apparatus - Red square: Heating chamber; Blue square: Master die; Yellow square: Flexible sheet

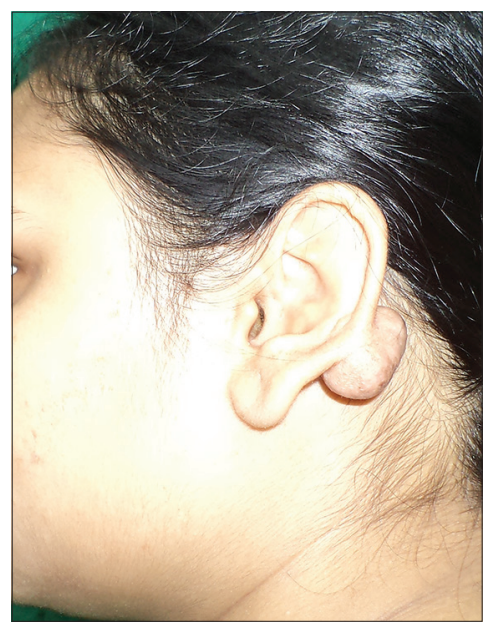

Figure 7: Large deforming helical keloid performed. Fourteen days post-operative, after suture removal, impression was made of the left ear with putty and light body silicone impression material as described earlier. Master die was obtained, and 2-mm ethylene vinyl films (Bioplast ${ }^{\circledR}$ ) was adapted as previously mentioned to fabricate the splint. The fit of the splint was checked on the patient to assess comfort and self-retention using undercuts [Figure 8]. The patient received intralesional triamcinolone at $10 \mathrm{mg} / \mathrm{cm}^{2}$ every 3 weeks for four visits. She was instructed to wear the splint for 12 months post-operative and was reviewed monthly for compliance with no keloid recurrence at 1 year post-operative visit [Figure 9].

\section{DISCUSSION}

Helical rim keloids are difficult to excise completely as the helical cartilage is easily deformed by surgery and helical skin can sparingly be mobilised for tension free closure. Intralesional steroids are the most frequent adjuvant therapy to avoid recurrence; however, it is accompanied

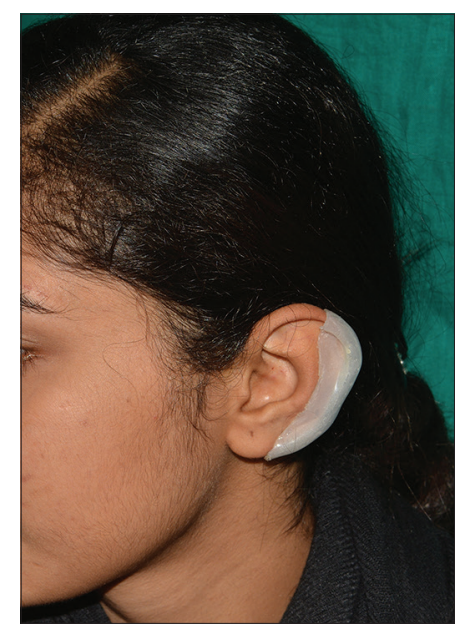

Figure 6: Patient wearing splint immediate post-operative

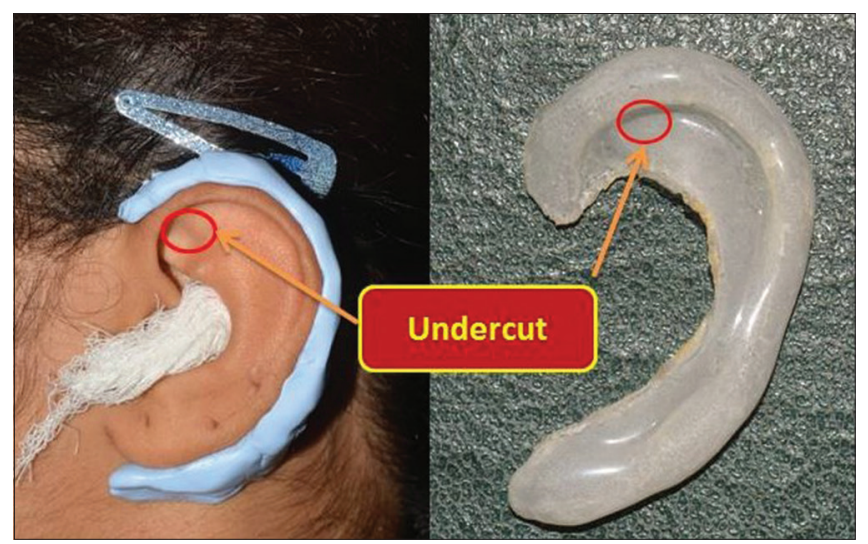

Figure 8: Undercuts in impression and in final splint 


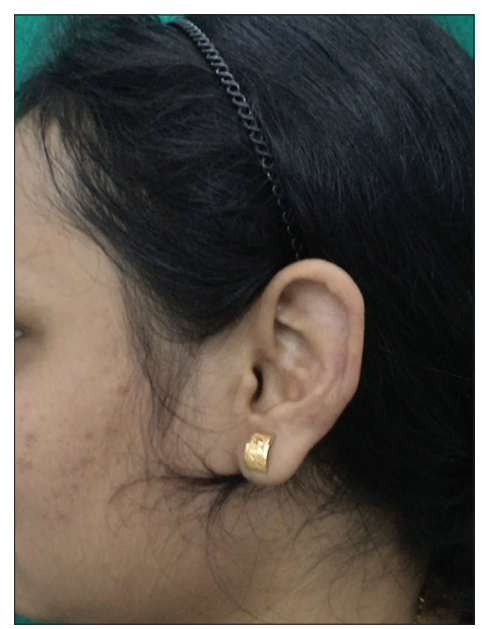

Figure 9: No recurrence and helical shape maintained at 1 year

by skin atrophy and telangiectasia, not to mention the pain associated with injecting within the narrow confines of helical soft tissue.

Compression following the surgical excision is an effective treatment option. Compression reduces tissue metabolism and fibroblast proliferation; it has also been shown to increase collagenase activity and induce mast cell stabilisation. These processes, in turn, lead to attenuation of hypertrophy and pruritic symptoms. Compression has been combined with intralesional steroids as multimodal post-operative therapy.

Mercer and Studd ${ }^{[1]}$ devised the oyster splint which provided adjustable compression between two Perspex shells held by nylon screws, worn for up to 12 months. Chalian et al. ${ }^{[2]}$ prepared shells of acrylic resin held together by nylon screws. Chrisostomidis et al.[3] presented a form pressure garment worn for 25 weeks. Hassel et $a .^{[4]}$ placed a silicone sheet below modified oyster shells of cold resin and combined with intralesional steroids for a duration of 6 months. Yüzbasioglu ${ }^{[5]}$ used acrylic shells activated by a Hyrax screw for $12 \mathrm{~h}$ a day for 6 months. However, the real danger of inadequate patient compliance with increasing device complexity and the risk of localised pressure ulceration with effective pressure range being only between 24 and $30 \mathrm{mmHg}$ cannot be underestimated.

Hurtado and Crowther ${ }^{[6]}$ showed that a 'passive' PMMA stent fabricated to conform to the established volume of the helical rim will confine the soft tissue in its internal dimension. These 'passive' stents give no space for recurrent growth of the keloid and thus, replaces external compression with internal compression. In addition, they are inexpensive and easily removed and applied by the patient. They avoid the risk of inflammation and necrosis which, in an operated ear, would lead to a delay in results and possible secondary surgery. Sand et al. ${ }^{|7|}$ created a passive silicone splint which he combined with intralesional steroids for 12 months of therapy. Rathee and $\mathrm{Kundu}^{[8]}$ combined a passive PMMA shell splint with magnets as post-operative adjuvant therapy. Kadouch et al. ${ }^{\left[{ }^{[9]}\right.}$ in a series of 23 patients, used a PMMA splint with retaining metallic spring incorporated on the helical rim and showed 83\% non-recurrence after 18 months of therapy. Yigit et al.$^{[10]}$ fabricated a negative silicone mould to the helical rim post-excision and combined it with a silicone sheet and headband.

This article describes two cases in which impression was made in different situations. One prior to surgery which required a mock surgery in the master die and the other case was done after the surgery. Mock surgery, in the first case, enabled the prosthodontist to fabricate and fit the splint on the first post-operative day after dressing change. The use of silicone impression material recorded finer details and allowed painless removal. The impression recorded the undercuts in the ear thus providing retention for the splints.

The flexible film used in this technique is an ethylene vinyl acetate material, which is used by dentists for the fabrication of soft splints and bleaching trays. It is biocompatible and conformable to helical contour. The splint easily slides on the helical rim where it is needed while maintaining a low profile below the hairline and not obstructing the auditory meatus. It is a resilient material and retains its shape and volume by its natural elasticity. The splint can be fabricated by any commercial dental laboratory from impressions of the affected ear.

\section{CONCLUSION}

The article presents an ethylene vinyl acetate film splint which can be effectively used for splint therapy in keloids. The device is easy to use, washable and safe. This combination of surgical excision and splinting respects the delicate anatomy of the helical rim and is a simple solution to maintaining helical shape. Providing skin coloration to the splint would improve patient acceptability and compliance.

\section{Financial support and sponsorship Nil.}




\section{Conflicts of interest}

There are no conflicts of interest.

\section{REFERENCES}

1. Mercer DM, Studd DM. "Oyster splints": A new compression device for the treatment of keloid scars of the ear. $\mathrm{Br} J$ Plast Surg 1983;36:75-8.

2. Chalian VA, Bennett JE, Sayoc AM, Ghalichebaf M. Auricular compression stent. J Prosthet Dent 1985;54:560-3.

3. Chrisostomidis C, Konofaos P, Chrisostomidis G, Vasilopoulou A, Dimitroulis D, Frangoulis $M$, et al. Management of external ear keloids using form-pressure therapy. Clin Exp Dermatol 2008;33:273-5.

4. Hassel JC, Roberg B, Kreuter A, Voigtländer V, Rammelsberg P, Hassel AJ. Treatment of ear keloids by compression, using a modified oyster-splint technique. Dermatol Surg 2007;33:208-12.

5. Yüzbasioglu E. Reverse activated hyrax pressure appliance for treatment of a keloid located at auricula helix. J Prosthodont 2013;22:509-12.

6. Hurtado AJ, Crowther DS. Methyl methacrylate stent for prevention of postexcisional recurrent ear keloid. J Prosthet Dent 1985;54:245-50.

7. Sand M, Sand D, Boorboor P, Mann B, Altmeyer P, Hoffmann K, et al. Combination of surgical excision and custom designed silicon pressure splint therapy for keloids on the helical rim. Head Face Med 2007;3:14

8. Rathee M, Kundu R. Magnet-retained prophylactic appliance for post-excisional pressure therapy and custom-made acrylic therapeutic pressure appliance for auricular keloid: A clinical report. J Surg Tech Case Rep 2014;6:29-32.

9. Kadouch DJ, van der VeerWM, Kerkdijk D, Mahdavian Delavary B, Niessen FB. Postoperative pressure therapy of ear keloids using a custom-made methyl methacrylate stent. Dermatol Surg 2010;36:383-5.

10. Yigit B, Yazar M, Alyanak A, Guven E. A custom-made silicon mold for pressure therapy to ear keloids. Aesthetic Plast Surg 2009;33:849-51. 